Jpn. J. Pharm. Health Care Sci.

一般論文 33(12) 1013-1019(2007)

\title{
Stability of Magnesium Oxide Products in Single-dose Packages
}

\author{
Ryusho Oka ${ }^{* 12}$, Koji Uwai ${ }^{2}$, Teiko Toyoguchi ${ }^{1}$, T adashi Shiraishi ${ }^{1}$, \\ Yoshito Nakagawa ${ }^{1}$ and Mitsuhiro Takeshita ${ }^{2}$ \\ Division of Pharmacy, Yamagata University Hospital ${ }^{1}$ \\ Department of Pharmaceutics, Tohoku Pharmaceutical University ${ }^{2}$
}

Received July 5, 2007

( A ccepted October 15, 2007 )

Recently, the use of generic drugs has been steadily increasing, and more medical institutions are dispensing single-dose packages to improve compliance among elderly patients. In view of this, we prepared single-dose packages for several generic products containing the laxative agent magnesium oxide and compared their stability with that of an original product when the packages were stored long-term under constant conditions.

We examined a total of four types of product-two plain tablets ( $\mathrm{ML}$ and $\mathrm{MM}$ ) and a film-coated tablet (KM) as the ge neric products, and subtle granules (SM) as the original product. They were evaluated with respect to appearance change as well as quantitative test, hardness test (SM excluded) disintegration test (SM excluded) and dissolution test results after storage for 90 days under three sets of constant conditions $\left(25^{\circ} \mathrm{C}\right.$ and $75 \% \mathrm{RH}, 30^{\circ} \mathrm{C}$ and $75 \% \mathrm{RH}, 40^{\circ} \mathrm{C}$ and $75 \% \mathrm{RH}$ ).

The appearance of the products did not change under any of the sets of conditions and the results of the quantitative test showed an average content of more than 96\%. However, hardness increased under all of the storage conditions and there was a significant difference among the three product types in this regard. In the disintegration test, a delayed collapse was noted for all products except ML under each of the set of conditions. In the dissolution test, as compared with SM, the elution rate for KM was significantly lower, and it tended to be lower with ML and MM as well.

In our study, as we noted differences among the 4 types of product as regards physicochemical stability when packed in single dose packages, generic products must be carefully selected with regard to stability when adopting them for specific dispensing strategies.

Key words — generic drug, magnesium oxide, single-dose package, stability, disintegration test, dissolution test

\section{Introduction}

Japan is an aging society, and health-care costs are rising year by year. As part of cost-cutting plans, the Japanese government is encouraging the use of generic drugs. In advanced-treatment hospitals, introduction of the Diagnosis Procedure Combination has increased the use of generic products and reduced medical expenses. As of A pril 2006, proprietary drugs can easily be substituted with generic drugs. Treatment fees have also been revised to reward pharmacies for providing information on dispensed drugs to pa tients and for informing the medical institution that issued the prescription of the actual brand of drug dispensed. A dditionally, the use of generic drugs has been encouraged by advertising. This advertising has improved the name recognition of less expensive generic drugs. However, medical workers are still uneasy about the quality and availability of generic drugs and the amount of information available about them. In fact, there are reports of differences in quality be tween proprietary and generic drugs ${ }^{1-3)}$.

Until recently, proprietary magnesium oxide granules were routinely used to produce a lapactic or antacid effect. However, several tabletted magnesium oxide preparations have been developed. For this reason, medical institutions have employed a single-dose packaging system. While this system facilitates patient compliance with the proper dosages of multiple drugs, neither the quality of drugs in this format nor the resultant stability has been adequately tested. Although there have been several reports about the oral sensa tion of magnesium oxide tablets ${ }^{4-6)}$, the quality of drugs and their stability within a single dose packaging system have not been carefully addressed. Thus, in this study, we compared the stability of proprietary (granules) and generic magnesium oxide preparations produced by several manufactures in a single-dose packaging system after storage under various conditions. 


\section{Material and Methods}

\section{Samples}

As a proprietary drug, 3 production lots (Lot No.705783, 705784 , and 605743 ) of fine granules of magnesium oxide (anonymity : SM fine granules, official drug, content 96\%) were used. A s generic drugs, 3 production lots of a uncoated tablet of magnesium oxide (anonymity : ML tablet; content, $330 \mathrm{mg}$ per tablet; Lot No.505025, 505026, and 605027; and anonymity: MM tablet; content, $330 \mathrm{mg}$ per tablet; Lot No.051005, 052009, and 053006) and 1 production lot (Lot No.440402) of a film-coated tablet (anonymity : KL tablet; content, $330 \mathrm{mg}$ per tablet) were used. All other chemicals were of chemical grade.

\section{General method}

SM fine granules (divided into 0.33 g doses [dividing pa per: Towa new mat, TOSHO, powder packaging system: AR-N 9090, TOSHO ]) and other generic tablets (6 tablets divided into a single-dose packages ([dividing paper : Towa new mat, TOSHO ; single-dose packaging system: MAINTOPRA $4001 \mathrm{SR}, \mathrm{TOSHO}]$ ) were stored in darkness under the following conditions: $25 \pm 22^{\circ} \mathrm{C}$ and $75 \pm 5 \%$ relative humidity $(\mathrm{RH}), 30 \pm 22^{\circ} \mathrm{C}$ and $75 \pm 5 \% \mathrm{RH}$, and $40 \pm 22^{\circ} \mathrm{C}$ and $75 \pm 5 \% \mathrm{RH}$. Samples were obtained after 0, 7, 14, 30, 60, and 90 days of storage. The samples of each production lot were examined with 5 tests: change in appearance, quantita tive test, hardness test, disintegration test, and dissolution test.

1) Changes in appearance

The samples were observed through the paper.

2) Quantitative test

Twenty tablets of each sample were weighed and reduced to a powder. The equivalent of approximately $1.0 \mathrm{~g}$ of magnesium oxide was precisely weighed out and heated at 900 ${ }^{\circ} \mathrm{C}$ for $2 \mathrm{hrs}$. After cooling, the magnesium oxide was dis solved in $20 \mathrm{~mL}$ of $\mathrm{H}_{2} \mathrm{O}$ and $24 \mathrm{~mL}$ of diluted $\mathrm{HCl}$ aqueous solution, and $\mathrm{H}_{2} \mathrm{O}$ was added to accurately make up a volume of $100 \mathrm{~mL}$ (solution 1). To $5 \mathrm{~mL}$ of solution $1,50 \mathrm{~mL}$ of $\mathrm{H}_{2} \mathrm{O}$ and $10 \mathrm{~mL}$ of a buffer solution of $\mathrm{NH}_{4} \mathrm{OH}-\mathrm{NH}_{4} \mathrm{Cl}$ ( $\mathrm{pH}$ 10.7) were added. The solution was titrated with $0.05 \mathrm{M}$ disodium ethylenediaminetetraacetate (EDTA) (solution 2) and $0.04 \mathrm{~g}$ of Eriochrome black $\mathrm{T} /$ sodium chloride as an indicator. A blank was produced, and background corrections were made for all measurements. The magnesium oxide was quantified by subtracting the volume of solution 2 corresponding to the calcium oxide in the purity test (see below) from the consumption of solution 2 in this test. All experiments were performed in triplicate.

For the purity test, a mixture of $25 \mathrm{~mL}$ of solution 1, 280 $\mathrm{mL}$ of $\mathrm{H}_{2} \mathrm{O}, 3 \mathrm{~mL}$ of a $20 \%$ aqueous solution of L-tartaric acid, $10 \mathrm{~mL}$ of a $30 \%$ aqueous solution of 2, 2', 2' nitromethanol, and $10 \mathrm{~mL}$ of an $8 \mathrm{M}$ aqueous solution of potassium hydroxide was left to stand for $5 \mathrm{~min}$. The solution was titrated with $0.01 \mathrm{M}$ EDTA ; the end point was marked by a change in color from red-purple to blue. A blank was made, and background corrections were done for all meas urements.

3) Hardness test

Ten tablets of each sample were used in the hardness test (hardness testing machine:PTB-3411E, PHARMA TEST, Hainburg, Germany, greatest measured value : $30 \mathrm{kp}$ ).

4) Disintegration test

A ccording to the method of the Japanese Pharmacopoeia, 14 th edition ${ }^{7}$, six tablets of each sample were subjected to a disintegration test (disintegration testing machine:HM-6D, Miyamoto Riken Co. Ltd., Osaka, Japan). Briefly, the test was conducted with $\mathrm{H}_{2} \mathrm{O}$ (test solution) at $37 \pm 2^{\circ} \mathrm{C}$ for 30 min ( $\mathrm{ML}$ and $\mathrm{MM}$ tablets) or $60 \mathrm{~min}$ (KM tablets). A tablet was considered to have passed the test, if no residue, only a spongy substance, or only a small amount of a soft or muddy residue remains in the test tube. If only one tablet re mained intact or if fragments of the sample was observed in the tube, the test was repeated with an additional six tablets.

5) Dissolution test

The rotatory basket method, as described in the Japanese Pharmacopoeia, 14 th edition ${ }^{8)}$, was used for the dissolution test (dissolution testing machine: NTR-6100A, Toyama Sangyo Co. Ltd., Osaka, Japan). The test was conducted with the first solution ( $\mathrm{pH} 1.2$, test solution) at $37 \pm 0.5^{\circ} \mathrm{C}$ for $5,10,20,30$, and $60 \mathrm{~min}$. The paddle rotation speed was $50 \mathrm{rpm}$. The contents of the samples were analyzed with an ion chromatographic method (ion chromatograph: DX-120, auto-sampler : A S 3500, suppressor : CSRS-ULTRA, Dionex Corp., Sunnyvale CA, USA,).

The solution $(2.5 \mathrm{~mL})$ was filtered through a $0.2-\mu \mathrm{m}$ cartridge membrane filter, and the first $0.5 \mathrm{~mL}$ of filtrate was removed. The remaining $2.0 \mathrm{~mL}$ of filtrate was used as a sample (successively, replenishing the lost $2.5 \mathrm{~mL}$ of test soIution to the bucket). Next, $1.0 \mathrm{~mL}$ of $\mathrm{H}_{2} \mathrm{O}$ was added to the $0.5 \mathrm{~mL}$ of sample, and $5 \mathrm{~L}$ was subjected to ion chromatography with a Dionex IonPac CS $12 \mathrm{~A}$ column $(4 \times 250 \mathrm{~mm}$, 8.5u $\mathrm{m}$; Dionex Corp.) eluted with a $25 \mathrm{mM}$ methanesulfonic acid solution at $1.0 \mathrm{~mL} / \mathrm{min}$.

6) Statistic analysis

Data are given as meanst S.D..

Statistical significance was evaluated by one-way ANOVA, and multiple comparisons were performed by Scheffe's method. Statistical differences between groups were evaluated with Student's t-test. Differences with $P<$ 0.05 were considered significant.

\section{Results}

\section{Changes in appearance}

Both the proprietary and generic drugs stored at $25^{\circ} \mathrm{C}$ and $75 \% \mathrm{RH}, 30^{\circ} \mathrm{C}$ and $75 \% \mathrm{RH}$, or $40^{\circ} \mathrm{C}$ and $75 \% \mathrm{RH}$ for 90 days were unchanged in color tone or shape.

\section{Quantitative test}

The average content of both the proprietary and generic drugs stored at $25^{\circ} \mathrm{C}$ and $75 \% \mathrm{RH}, 30^{\circ} \mathrm{C}$ and $75 \% \mathrm{RH}$, or 
$40^{\circ} \mathrm{C}$ and $75 \% \mathrm{RH}$ for 90 days was more than $96 \%$ (Table 1). This result meets the approval standard for pharmaceutical products defined by each pharmaceutical company (95 $\%-105 \%)$.

\section{Hardness test}

a) Lot-to-lot variation

For ML tablets, there were significant differences between the lots stored at $40^{\circ} \mathrm{C}$ and $75 \% \mathrm{RH}$ within 7 days, at $30^{\circ} \mathrm{C}$ and $75 \% \mathrm{RH}$ on day 0 , and at $25^{\circ} \mathrm{C}$ and $75 \% \mathrm{RH}$ on day 0 , but there were no differences thereafter (Fig. 1). For MM tablets, there were significant differences for the entire period (Fig. 2).

b) Product-to-product variation

The average degree of hardness (ML tablets, 3lots; MM tablets, 3 lots; and KM tablets, 1 lot) was compared. All generic drugs became harder with time at $25^{\circ} \mathrm{C}$ and $75 \% \mathrm{RH}$, $30^{\circ} \mathrm{C}$ and $75 \% \mathrm{RH}$, and $40^{\circ} \mathrm{C}$ and $75 \% \mathrm{RH}$ (Fig. 3). ML tablets were significantly harder than $\mathrm{MM}$ tablets, except on day 0 and on day 90 at $40^{\circ} \mathrm{C}$ and $75 \% \mathrm{RH}$. The degree of hardness of $\mathrm{KM}$ tablets was beyond the measurable limit af- ter 30 days at $25^{\circ} \mathrm{C}$ and $75 \% \mathrm{RH}, 14$ days at $30^{\circ} \mathrm{C}$ and $75 \%$ $\mathrm{RH}$, and 7 days at $40^{\circ} \mathrm{C}$ and $75 \% \mathrm{RH}$ (Fig. 3).

\section{Disintegration test}

$\mathrm{ML}$ tablets disintegrated within $4 \mathrm{~min}$. under all conditions, even when stored for 90 days, and so met the standard.

At $25^{\circ} \mathrm{C}$ and $75 \% \mathrm{RH}, \mathrm{MM}$ tablets disintegrated at 14 sec. when stored for 30 days, at $14 \mathrm{~min}$. $30 \mathrm{sec}$. when stored for 60 days, and after more than $30 \mathrm{~min}$ when stored for more than 90 days and, therefore, did not meet the standard. At $30^{\circ} \mathrm{C}$ and $75 \% \mathrm{RH}, \mathrm{MM}$ tablets disintegrated at $10 \mathrm{sec}$. when stored for 14 days, but when stored for more than 30 days, 2 of 3 lots of MM tablets disintegrated after more than $30 \mathrm{~min}$ and, therefore, did not meet the standard. At $40^{\circ} \mathrm{C}$ and $75 \% \mathrm{RH}, \mathrm{MM}$ tablets disintegrated at $13 \mathrm{sec}$. when stored for 7 days and at $6 \mathrm{~min}$. $55 \mathrm{sec}$. when stored for 14 days, but when stored for more than 30 days, they disintegrated after more than $30 \mathrm{~min}$ and, therefore, did not meet the standard.

At $25^{\circ} \mathrm{C}$ and $75 \% \mathrm{RH}, \mathrm{KM}$ tablets disintegrated at $8 \mathrm{~min}$.

Table 1. Results of Quantification Tests of Each Drug during Storage in Single-dose Packages $(n=3)$.

\begin{tabular}{|c|c|c|c|c|c|c|c|c|}
\hline \multicolumn{3}{|c|}{ Items } & \multicolumn{4}{|c|}{$25^{\circ} \mathrm{C}$ and $75 \% \mathrm{RH}$} & & \\
\hline Class & Code & Lot No. & Start & Day 30 & Day 60 & Day 90 & & \\
\hline & & 705783 & $98.3 \pm 0.4$ & $98.7 \pm 0.1$ & $98.6 \pm 0.4$ & $98.7 \pm 0.2$ & & \\
\hline \multirow[t]{5}{*}{ Proprietary } & $\mathrm{SM}$ & 705784 & $98.5 \pm 0.2$ & $98.9 \pm 0.3$ & $398.7 \pm 0.3$ & $98.7 \pm 0.2$ & & \\
\hline & & 605743 & $98.1 \pm 0.0$ & $98.7 \pm 0.2$ & $-98.5 \pm 0.2$ & $98.7 \pm 0.4$ & & \\
\hline & & 505025 & $100.1 \pm 0.2$ & $101.6 \pm 0.1$ & $99.7 \pm 0.1$ & $101.3 \pm 0.1$ & & \\
\hline & $\mathrm{ML}$ & 505026 & $99.7 \pm 0.3$ & $101.3 \pm 0.1$ & $101.1 \pm 0.1$ & $100.9 \pm 0.4$ & & \\
\hline & & 605027 & $100.6 \pm 0.3$ & $101.4 \pm 0.3$ & $101.4 \pm 0.2$ & $100.9 \pm 0.1$ & & \\
\hline \multirow[t]{4}{*}{ Generic } & & 051005 & $97.2 \pm 0.1$ & $97.8 \pm 0.2$ & $97.6 \pm 0.1$ & $97.9 \pm 0.1$ & & \\
\hline & MM & 052009 & $97.5 \pm 0.2$ & $98.0 \pm 0.1$ & $97.9 \pm 0.1$ & $97.7 \pm 0.3$ & & \\
\hline & & 053006 & $97.3 \pm 0.1$ & $98.0 \pm 0.1$ & $97.6 \pm 0.4$ & $98.2 \pm 0.1$ & & \\
\hline & $\mathrm{KM}$ & 440402 & $98.1 \pm 0.2$ & $98.9 \pm 0.2$ & $-98.2 \pm 0.2$ & $97.7 \pm 0.1$ & & \\
\hline \multicolumn{3}{|c|}{ Items } & \multicolumn{6}{|c|}{$30^{\circ} \mathrm{C}$ and $75 \% \mathrm{RH}$} \\
\hline Class & Code & Lot No. & Start & Day 7 & Day 14 & Day 30 & Day 60 & Day 90 \\
\hline & & 705783 & $98.3 \pm 0.4$ & $98.2 \pm 0.2$ & $98.7 \pm 0.1$ & $99.0 \pm 0.7$ & $99.0 \pm 0.2$ & $98.7 \pm 0.2$ \\
\hline \multirow[t]{2}{*}{ Proprietary } & SM & 705784 & $98.5 \pm 0.2$ & $98.7 \pm 0.2$ & $98.7 \pm 0.2$ & $99.6 \pm 0.6$ & $99.2 \pm 0.3$ & $98.7 \pm 0.1$ \\
\hline & & 605743 & $98.1 \pm 0.0$ & $98.8 \pm 0.2$ & $99.0 \pm 0.3$ & $99.6 \pm 0.1$ & $99.0 \pm 0.3$ & $98.6 \pm 0.1$ \\
\hline \multirow{7}{*}{ Generic } & & 505025 & $100.1 \pm 0.2$ & $100.1 \pm 0.2$ & $100.7 \pm 0.1$ & $100.7 \pm 0.2$ & $101.0 \pm 0.1$ & $101.5 \pm 0.1$ \\
\hline & ML & 505026 & $99.7 \pm 0.3$ & $100.2 \pm 0.1$ & $101.0 \pm 0.1$ & $99.9 \pm 0.2$ & 10 & 10 \\
\hline & & 605027 & $100.6 \pm 0.3$ & $100.8 \pm 0.3$ & $99.1 \pm 0.1$ & $99.6 \pm 0.1$ & $99.4 \pm 0.1$ & $101.7 \pm 0.2$ \\
\hline & & 051005 & $97.2 \pm 0.1$ & $97.6 \pm 0.1$ & $97.3 \pm 0.0$ & $98.1 \pm 0.2$ & $97.7 \pm 0.4$ & $98.4 \pm 0.4$ \\
\hline & MM & 052009 & $97.5 \pm 0.2$ & $97.4 \pm 0.2$ & $97.6 \pm 0.2$ & $98.7 \pm 0.3$ & $98.4 \pm 0.1$ & $98.4 \pm 0.1$ \\
\hline & & 053006 & $97.3 \pm 0.1$ & $97.2 \pm 0.2$ & $98.3 \pm 0.2$ & $98.1 \pm 0.3$ & $98.7 \pm 0.3$ & $98.7 \pm 0.3$ \\
\hline & KM & 440402 & $98.1 \pm 0.2$ & $98.1 \pm 0.1$ & $98.1 \pm 0.2$ & $98.4 \pm 0.6$ & $97.4 \pm 0.4$ & $96.3 \pm 0.3$ \\
\hline \multicolumn{3}{|c|}{ Items } & \multicolumn{6}{|c|}{$40^{\circ} \mathrm{C}$ and $75 \% \mathrm{RH}$} \\
\hline Class & Code & Lot No. & Start & Day 7 & Day 14 & Day 30 & Day 60 & Day 90 \\
\hline \multirow{3}{*}{ Proprietary } & & 705783 & $98.3 \pm 0.4$ & $98.7 \pm 0.1$ & $98.9 \pm 0.2$ & $98.9 \pm 0.1$ & $99.0 \pm 0.2$ & $98.7 \pm 0.4$ \\
\hline & $\mathrm{SM}$ & 705784 & $98.5 \pm 0.2$ & $99.2 \pm 0.3$ & $98.9 \pm 0.1$ & $98.5 \pm 0.1$ & $98.9 \pm 0.2$ & $98.9 \pm 0.3$ \\
\hline & & 605743 & $98.1 \pm 0.0$ & $99.0 \pm 0.4$ & $98.6 \pm 0.2$ & $98.6 \pm 0.2$ & $98.8 \pm 0.1$ & $98.9 \pm 0.3$ \\
\hline \multirow{7}{*}{ Generic } & & 505025 & $100.1 \pm 0.2$ & $100.2 \pm 0.7$ & $100.0 \pm 0.1$ & $101.2 \pm 0.5$ & $100.9 \pm 0.1$ & $101.0 \pm 0.3$ \\
\hline & ML & 505026 & $99.7 \pm 0.3$ & $100.1 \pm 0.1$ & $99.9 \pm 0.3$ & $100.7 \pm 0.2$ & $101.4 \pm 0.1$ & $100.8 \pm 0.2$ \\
\hline & & 605027 & $100.6 \pm 0.3$ & $101.0 \pm 0.2$ & $101.5 \pm 0.1$ & $100 \pm 0.2$ & $100.3 \pm 0.1$ & $100.8 \pm 0.2$ \\
\hline & & 051005 & $97.2 \pm 0.1$ & $97.8 \pm 0.2$ & $98.1 \pm 0.1$ & $97.3 \pm 0.1$ & $97.6 \pm 0.1$ & $97.9 \pm 0.2$ \\
\hline & MM & 052009 & $97.5 \pm 0.2$ & $97.8 \pm 0.2$ & $97.2 \pm 0.1$ & $97.0 \pm 0.1$ & $97.7 \pm 0.1$ & $97.5 \pm 0.2$ \\
\hline & & 053006 & $97.3 \pm 0.1$ & $97.3 \pm 0.1$ & $98.0 \pm 0.1$ & $97.5 \pm 0.2$ & $98.1 \pm 0.2$ & $97.7 \pm 0.4$ \\
\hline & $\mathrm{KM}$ & 440402 & $98.1 \pm 0.2$ & $97.2 \pm 0.1$ & $97.2 \pm 0.1$ & $97.7 \pm 0.2$ & $96.7 \pm 0.1$ & $98.3 \pm 0.4$ \\
\hline
\end{tabular}





Fig 1. Daily Changes in Hardness of the ML Tablet in Single dose Packages.

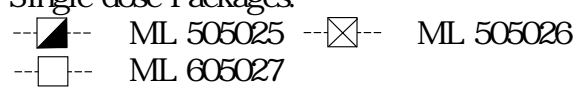

Storage conditions : A : $25^{\circ} \mathrm{C}$ and $75 \% \mathrm{RH}$; B : $30^{\circ} \mathrm{C}$ and $75 \% \mathrm{RH} ; \mathrm{C}: 40^{\circ} \mathrm{C}$ and $75 \% \mathrm{RH}$. mean \pm S.D. $(n=10){ }^{*} p<0.05$

$54 \mathrm{sec}$. when stored for 7 days but when stored over 7 days, disintegrated after more than $30 \mathrm{~min}$ and, therefore, did not meet the standard. At $30^{\circ} \mathrm{C}$ and $75 \% \mathrm{RH}, \mathrm{KM}$ tablets disintegrated at $12 \mathrm{~min}$. $29 \mathrm{sec}$. when stored for 7 days, but when stored for more than 14 days, disintegrated after more than $60 \mathrm{~min}$ and, therefore, did not meet the standard. At $40^{\circ} \mathrm{C}$ and $75 \% \mathrm{RH}$, when stored for more than 30 days, they dis integrated after more than $60 \mathrm{~min}$ and, therefore, did not meet the standard (Table 2).

\section{Dissolution test}

a) Dissolution behavior

The time course of the dissolution of drugs stored at $40^{\circ} \mathrm{C}$ and $75 \% \mathrm{RH}$ for 90 days is shown in Fig. 4. The dissolution rates increased with dissolution time. After $2 \mathrm{hrs}$, disso-
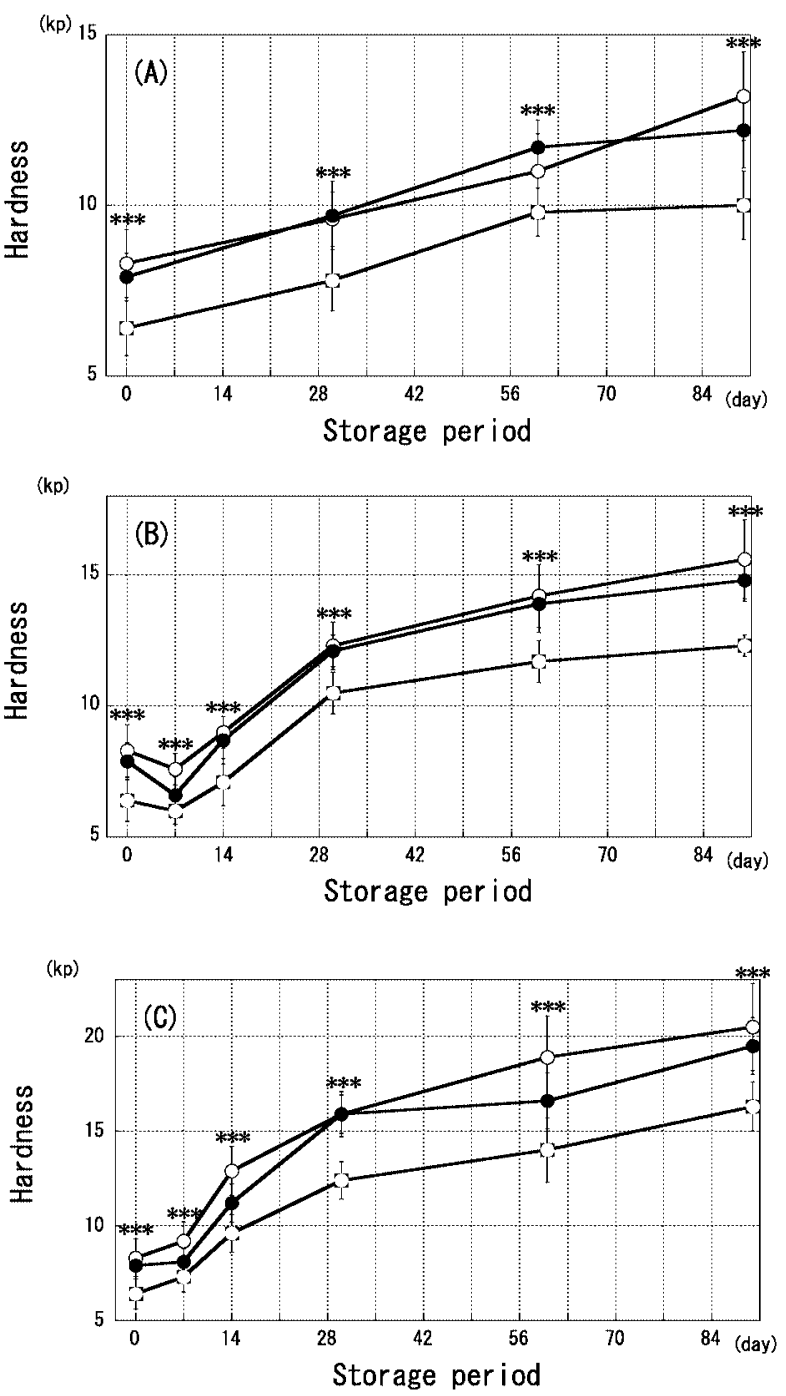

Fig 2. Daily Changes in Hardness of the MM Tablet in Single-dose Packages.

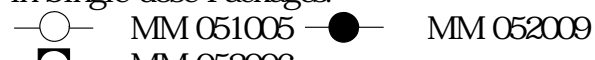

- : : MM 053006

Storage conditions: A : $25^{\circ} \mathrm{C}$ and $75 \% \mathrm{RH} ; \mathrm{B}$ :

$30^{\circ} \mathrm{C}$ and $75 \% \mathrm{RH} ; \mathrm{C}: 40^{\circ} \mathrm{C}$ and $75 \% \mathrm{RH}$. mean \pm S.D. $(n=10){ }^{* * *} p<0.001$

Iution rates for $\mathrm{SM}$ granules, ML tablets, and $\mathrm{MM}$ tablets were $71.8 \pm 2.6 \%, 63.1 \pm 1.9 \%$, and $50.5 \pm 2.1 \%$, respectively. In contrast, the dissolution rate for $\mathrm{KM}$ tablets was only $11.3 \pm 0.3 \%$.

b) V ariation among lots

SM granules showed no differences in the dissolution rate among product lots ( $\mathrm{n}=3$ for each lot). ML tablets showed significant differences in the dissolution rate between product lots when stored at $25^{\circ} \mathrm{C}$ and $75 \% \mathrm{RH}$ for 30 days $(n=$ 3 for each lot). MM tablets showed significant differences in the dissolution rate between product lots after being stored for 60 days at $25^{\circ} \mathrm{C}$ and $75 \% \mathrm{RH}$ and for 30 days at $40^{\circ} \mathrm{C}$ and $75 \% \mathrm{RH}$ ( $\mathrm{n}=3$ for each lot).

c) $V$ ariation among products

The average dissolution rates of products (ML tablets, 3 



Fig 3. Daily Changes in Hardness of Each Drug in Single dose Package.

- $\square--: M L \curlyvee$ : MM

$------:$ KM

Storage conditions: A : $25^{\circ} \mathrm{C}$ and $75 \% \mathrm{RH} ; \mathrm{B}$ : $30^{\circ} \mathrm{C}$ and $75 \% \mathrm{RH} ; \mathrm{C}: 40^{\circ} \mathrm{C}$ and $75 \% \mathrm{RH}$. mean \pm S.D. ${ }^{* *} p<0.01{ }^{* * *} p<0.001$ $\mathrm{ML}$ and $\mathrm{MM}$ : mean of 3 lots $(n=30) \mathrm{KM}$ : mean of 1 lot $(n=10)$

lots $(n=9) ;$ MM tablets, 3 lots $(n=9)$; and KM tablets, 1 lot $(n=3))$ were compared (Fig. 5). SM granules, a proprietary drug, had a stable dissolution rate of approximately 70 $\%$ under all conditions. ML tablets, like SM granules, had a stable dissolution rate, but the rate remained approximately $60 \%$. Additionally, ML tablets showed significant differences in the dissolution rate with $\mathrm{SM}$ granules at $25^{\circ} \mathrm{C}$ and at $40^{\circ} \mathrm{C}$ and $75 \% \mathrm{RH}$ after 30 and 60 days, and at $30^{\circ} \mathrm{C}$ and $75 \% \mathrm{RH}$ on days 14 and 30 . Although MM tablets dis solved at a rate the same as or a higher than that of SM granules at the start of the test under all conditions, a reduction in the rate was observed with time in storage at $25^{\circ} \mathrm{C}$ and $75 \% \mathrm{RH}$ on day 90 , at $30^{\circ} \mathrm{C}$ and $75 \% \mathrm{RH}$ after 60 days, and at $40^{\circ} \mathrm{C}$ and $75 \% \mathrm{RH}$ after 30 days. The dissolu- tion rates of the $\mathrm{KM}$ tablets were very low : $13.0 \%, 30.8 \%$, and $15.0 \%$ at $25^{\circ} \mathrm{C}$ and $75 \% \mathrm{RH}$ on day 30 , at $30^{\circ} \mathrm{C}$ and 75 $\% \mathrm{RH}$ on day 7 , and at $40^{\circ} \mathrm{C}$ and $75 \% \mathrm{RH}$ on day 7 , re spectively, and, thereafter, significant differences with SM granules were observed.

\section{Discussion}

Applications for the approval of generic drugs are accepted if they meet certain standards of drug approval and licensing procedures in Japan $2006^{\circ}$. In this study, we verified the equal quality of proprietary and generic drugs. Magnesium oxide preparations, for which the number of the pre scription have increased with the introduction of generic drugs, were examined under the limitation of fixed conditions in single-dose packages, and the stability of the proprietary and the generic drugs were compared.

Moisture, temperature, and light can all alter drug quality ; however, in view of the hygroscopicity of magnesium oxide, we fixed the test conditions as follows : $25^{\circ} \mathrm{C}$ and $75 \% \mathrm{RH}$, $30^{\circ} \mathrm{C}$ and $75 \% \mathrm{RH}$, and $40^{\circ} \mathrm{C}$ and $75 \% \mathrm{RH}$.

In the test of change in appearance and a quantitative test described by the method of the Japanese Pharmacopoeia, 14 th edition ${ }^{10)}$, no changes in color or quantity of each tablet were detected within 90 days with either proprietary or ge neric drugs. We assumed that the magnesium oxide had increased in weight through the absorption of moisture; however, $\mathrm{Mg}^{2+}$, being the main component and active ingredient of magnesium oxide preparations, is not easily changed by moisture and temperature. Thus, hardness, disintegration, and dissolution, all considered to be influenced by moisture and temperature, were investigated.

In the hardness test, every generic drug became harder as the length and temperature of storage increased. Because magnesium oxide absorbs moisture from the atmosphere ${ }^{10)}$, the hardness of the drugs increased in this way. The hardness of magnesium oxide in unopened packages was defined as having changed when the hardness changed by more than $30 \%$ and was more than $2.0 \mathrm{kgw}^{11)}$. $\mathrm{KM}$ tablets were significantly harder than the two other two generic drugs under all storage conditions from the early period. Additionally, ML tablets were significantly harder than $\mathrm{MM}$ tablets at all experimental periods, except for at $40^{\circ} \mathrm{C}$ and $75 \% \mathrm{RH}$ at 90 days. Considering the lot-to-lot variation in hardness, MM tablets showed a wide variation in hardness over all storage conditions and periods. On the other hand, ML tablets showed the wide variation in the early period of storage, but the wide variation was less with longer storage periods. The wide variation of hardness may have been due to differences in production processes.

Considering the hardening of the tablets, although there are no problems in their clinical usage, the hardening rate of the KM tablets differed from those of other generic drugs.

On the disintegration test, ML tablets met the standard of the Japanese Pharmacopoeia, 14 th edition, under all conditions tested, suggesting that the drug was of good quality in 
Table 2. Results of Disintegration Tests of Each Drug during Storage in Single dose Packages $(n=6)$.

\begin{tabular}{|c|c|c|c|c|c|c|c|}
\hline \multicolumn{2}{|c|}{ Items } & \multicolumn{4}{|c|}{$25^{\circ} \mathrm{C}$ and $75 \% \mathrm{RH}$} & & \\
\hline Code & Lot No. & Start & Day 30 & Day 60 & Day 90 & & \\
\hline \multirow{3}{*}{$\mathrm{ML}$} & 505025 & Conform & Conform & Conform & Conform & & \\
\hline & 505026 & Conform & Conform & Conform & Conform & & \\
\hline & 605027 & Conform & Conform & Conform & Conform & & \\
\hline \multirow{3}{*}{ MM } & 051005 & Conform & Conform & Conform & Non & & \\
\hline & 052009 & Conform & Conform & Conform & Non & & \\
\hline & 053006 & Conform & Conform & Conform & Non & & \\
\hline $\mathrm{KM}$ & 440402 & Conform & Non & Non & Non & & \\
\hline \multicolumn{2}{|c|}{ Items } & \multicolumn{6}{|c|}{$30^{\circ} \mathrm{C}$ and $75 \% \mathrm{RH}$} \\
\hline Code & Lot No. & Start & Day 7 & Day 14 & Day 30 & Day 60 & Day 90 \\
\hline \multirow{3}{*}{ ML } & 505025 & Conform & Conform & Conform & Conform & orm & orm \\
\hline & 505026 & Conform & Conform & Conform & Conform & Conform & Conform \\
\hline & 605027 & Conform & Conform & Conform & Conform & Conform & Conform \\
\hline \multirow{3}{*}{ MM } & 051005 & Conform & Conform & Conform & Non & Non & Non \\
\hline & 052009 & Conform & Conform & Conform & Non & Non & Non \\
\hline & 053006 & Conform & Conform & Conform & Conform & Non & Non \\
\hline $\mathrm{KM}$ & 440402 & Conform & Conform & Non & Non & Non & Non \\
\hline \multicolumn{2}{|c|}{ Items } & \multicolumn{6}{|c|}{$40^{\circ} \mathrm{C}$ and $75 \% \mathrm{RH}$} \\
\hline \multirow[t]{2}{*}{ Code } & Lot No. & Start & Day 7 & Day 14 & Day 30 & Day 60 & Day 90 \\
\hline & 505025 & Conform & Conform & Conform & Conform & Conform & Conform \\
\hline \multirow[t]{2}{*}{ ML } & 505026 & Conform & Conform & Conform & Conform & Conform & Conform \\
\hline & 605027 & Conform & Conform & Conform & Conform & Conform & Conform \\
\hline \multirow{3}{*}{ MM } & 051005 & Conform & Conform & Conform & Non & Non & Non \\
\hline & 052009 & Conform & Conform & Conform & Non & Non & Non \\
\hline & 053006 & Conform & Conform & Conform & Non & Non & Non \\
\hline $\mathrm{KM}$ & 440402 & Conform & Conform & Non & Non & Non & Non \\
\hline
\end{tabular}



Fig .4 . The Dissolution Rate of Each Drug after Storage at $40^{\circ} \mathrm{C}$ and $75 \% \mathrm{RH}$ for 90 days. mean \pm S.D. SM, ML and MM : mean of 3 lots $(n=9) K M:$ mean of 1 lot $(n=3)$

terms of disintegration without any relation to storage conditions. On the other hand, MM and $\mathrm{KM}$ tablets did not meet the criteria after a certain period. KM tablets were affected earlier than were MM tablets. In fact, water had not penetrated the center of the tablet even at the end of the disintegration test. Thus, it is difficult to imagine the effect of magnesium oxide at clinical dosages. From this point of view, we thought the dissolution test more accurately re flected the actual dissolution of magnesium oxide in the body.

For the dissolution test, there are no rules for magnesium oxide preparations in the Japanese Pharmacopoeia, 14 th edi$\operatorname{tion}^{8}$. However, to investigate differences in the dissolution rate between proprietary and generic drugs at clinical dos ages, we performed the dissolution test in a solution like re sembling gastric fluid ( $\mathrm{pH}$ 1.2). As a result, the dissolution rate of the proprietary drug was stable at about $70 \%$ under all storage conditions. Some ML tablets showed significantly lower dissolution rates than those of the proprietary drug under each storage condition, but the values were stable at about $60 \%$, and the dissolution profile was similar to that of the proprietary drug, suggesting that ML tablets are suitable for a single-dose packaging system. As it has been reported elsewhere ${ }^{6}$, MM tablets showed good solubility, in accordance with good disintegration, in our experiment, the dissoIution rate of the $\mathrm{MM}$ tablets was also higher than that of the proprietary drug from the early storage period. However, the dissolution rates decreased with the duration of storage, and were significantly decreased to $60 \%$ at $25^{\circ} \mathrm{C}$, and to 50 $\%$ at $30^{\circ} \mathrm{C}$ and $40^{\circ} \mathrm{C}$. The dissolution profiles were similar at $25^{\circ} \mathrm{C}$, but were clearly different at $30^{\circ} \mathrm{C}$ and $40^{\circ} \mathrm{C}$. Thus, MM tablets are not suitable for a single-dose packaging sys tem when stored at $30^{\circ} \mathrm{C}$ or higher. However, the dissolution rates of $\mathrm{KM}$ tablets differed from those of other generic drugs in that they decreased under all storage conditions from the early storage period. This is due to the drug form ; KM tablets are film-coated whereas others are uncoated. The dissolution profile significantly differed from that of the proprietary drug. These results suggest that this preparation is 

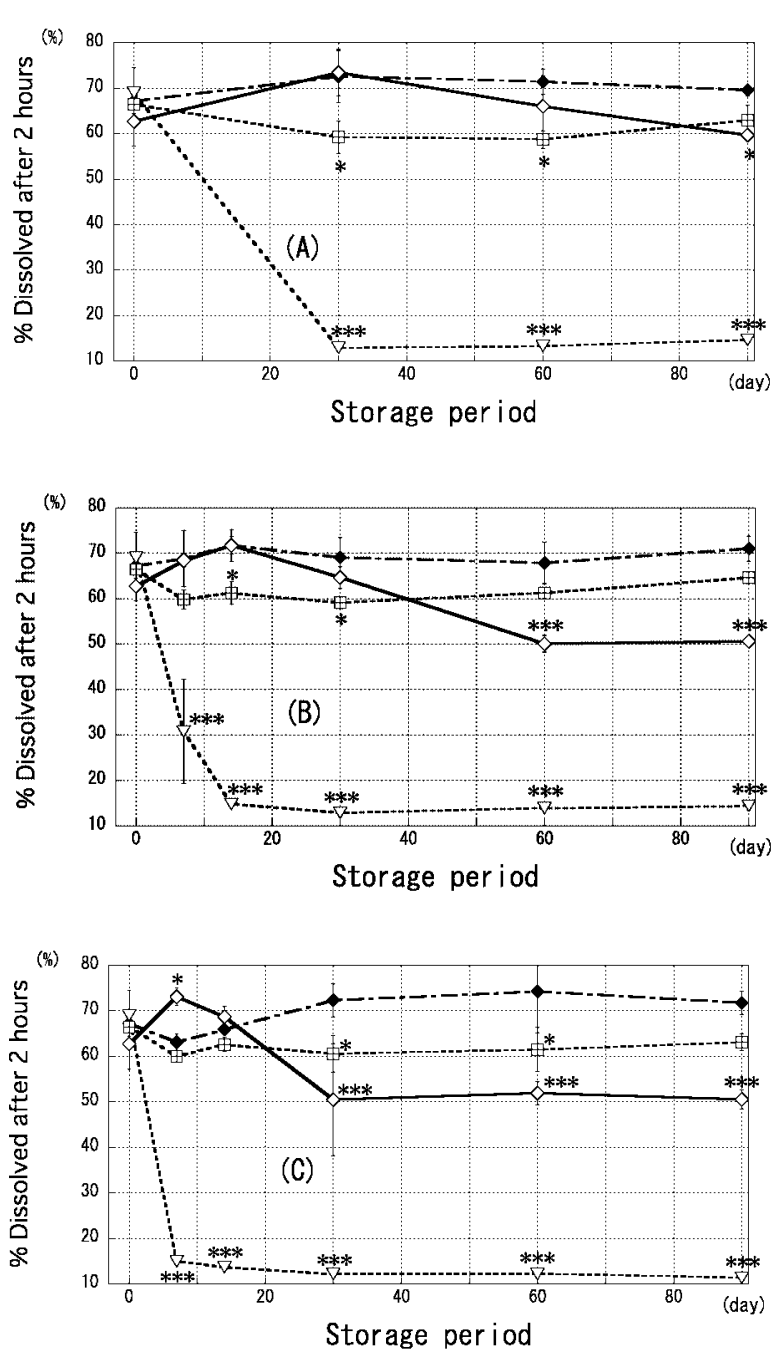

Fig .5. Daily Changes in the 120-minute Dissolution Rate of Each Drug in Single-dose Packages.

$$
\text { : SM - } \square-: \text { ML } \prec \text { : MM }
$$$$
-\nabla^{--}: \mathrm{KM}
$$

Storage conditions: A : $25^{\circ} \mathrm{C}$ and $75 \% \mathrm{RH}$; B : $30^{\circ} \mathrm{C}$ and $75 \% \mathrm{RH} ; \mathrm{C}: 40^{\circ} \mathrm{C}$ and $75 \% \mathrm{RH}$. mean \pm S.D. ${ }^{*} \mathrm{p}<0.05^{* * *} \mathrm{p}<0.001$ (Comparison with proprietary SM)

$\mathrm{SM}, \mathrm{ML}$, and $M M$ : mean of 3 lots $(n=9)$ KM : mean of 1 lot $(n=3)$

not suitable for a single dose packaging system.

In this study, we investigated the stability of proprietary and generic magnesium oxide products stored in single-dose packages. The results showed significant physical differences between the pharmaceutical products. Of the three generic drugs, only $M L$ tablets were as stable as the proprietary drug.

Because granules have problems with dosage and portability, generic products manufactured as tablets have a higher degree of usability. However, not all generic drugs approved by the Ministry of Health, Labour and Welfare have been subjected to long-term storage tests. Therefore, when medi- cal workers use generic drugs, they should carefully consider comprehensively quality, availability, and the amount of information available.

\section{References}

1) H. Koishi, K. Kanemoto, Y. Ikuno, T. Minouchi, T. Inoue, K. Hodohara, Y. Fujiyama, A. Y amaji, Fluctua tion in Therapeutic Control A ssociated with Interchange of Prednisolone Tablet Formulations: Assessment of Bioequivalence by Dissolution Test, Yakugaku Zashi, 122, 813-817 (2002).

2) T. Toyoguchi, J. Hosoya, M. Ebihara, F. Ojima, Y. Nakagawa, Y. Okamoto, N. Ootani, S. Torii, Comparisons of 8 Itraconazole preparations (1) - pharmaceutical Research - (in japanese), J. New Rem. Clin ., 54, 14011407 (2005).

3) T. Toyoguchi, J. Hosoya, M. Ebihara, F. Ojima, Y. Nakagawa, Y. Okamoto, N. Ootani, S. Torii, Comparisons of 8 Itraconazole preparations (2) - pharmacokinetics in Canines- (in japanese), J. New Rem. Clin., 54, 1408-1412 (2005).

4) R. Oka, M. Furukawa, T. Shiraishi, T. Shoji, Y. Naka gawa, Comparison of stability and drug impression on magnesium oxide tablet, Jpn. J. Med. Pharm. Sci., 49, 941-948 (2003).

5) Y. Komiya, Y. Y anagihara, Y. Y amazoe, K. Moriyama, The comparison of the stability with non-packaging condition and the sensation of oral administration in magnesium oxide tablets, Jpn. Pharmacol. Ther., 32, 31-36 (2004).

6) S. Inoue, M. Nakagawa, T. Baba, R. Chonan, M. Ojima, T. Kurusu, K. Hamatake, C. Hiruta, S. Hotta, N. Ejiri, A comparison of the use of fine granules of magnesium oxide with the use of manufactured tablets: re garding patient satisfaction, convenience and profitability, J. Jpn. Soc. Hosp. Pharm., 41, 867-871 (2005).

7) Japanese Pharmacopoeia Editing Committee., Commentary of the Japanese Pharmacopoeia", 14 th edition. $\mathrm{Hi}$ rokawa Publishing Co., Tokyo, 2001, pp. B 619-628.

8) Japanese Pharmacopoeia Editing Committee., Commentary of the Japanese Pharmacopoeia", 14 th edition, $\mathrm{Hi}$ rokawa Publishing Co., Tokyo, 2001, pp. B 679-695.

9) " Drug approval and licensing procedures in Japan 2006", Jiho, Inc., Tokyo, 2006, pp. 281-290\& pp. 304317.

10) Japanese Pharmacopoeia Editing Committee., Commentary of the Japanese Pharmacopoeia”, 14 th edition, $\mathrm{Hi}$ rokawa Publishing Co., Tokyo, 2001, pp.C 1392-1397.

11) Y. Nishioka, K. Ootsubo, K. Kihira, I. Sugimoto, H. Nakagawa, K. Mizuguchi, M. Miyamura, H. Okuda, H. Sotooka", Stability information in unpacked state of tablet and capsule agent, fourth Edition", ed by Japa nese society of hospital pharmacists, lyaku (Medicine and Drug) Journal Co., Ltd., Tokyo, 2005, pp. 7-11. 